\title{
Effects of the hydroalcoholic extract of Rosa damascena on hippocampal long-term potentiation in rats fed high-fat diet
}

\author{
Seyed Asaad Karimi ${ }^{1}{ }^{2 \dagger}$, Somayeh Komaki ${ }^{1 \dagger}$, Masoumeh Taheri ${ }^{1}$, Ghazaleh Omidi ${ }^{1}$, \\ Masoumeh Kourosh-Arami ${ }^{3,4}$, Iraj Salehi ${ }^{1}$ and Alireza Komaki ${ }^{1,2,5^{*}}$ (i)
}

\begin{abstract}
High-fat diets (HFDs) and obesity can cause serious health problems, such as neurodegenerative diseases and cognitive impairments. Consumption of HFD is associated with reduction in hippocampal synaptic plasticity. Rosa damascena (R. damascena) is traditionally used as a dietary supplement for many disorders. This study was carried out to determine the beneficial effect of hydroalcoholic extract of $R$. damascena on in vivo hippocampal synaptic plasticity (long-term potentiation, LTP) in the perforant pathway (PP) — dentate gyrus (DG) pathway in rats fed with an HFD. Male Wistar rats were randomly assigned to four groups: Control, $R$. damascena extract (1 g/kg bw daily for 30 days), HFD (for 90 days) and HFD + extract. The population spike (PS) amplitude and slope of excitatory post-synaptic potentials (EPSP) were measured in DG area in response to stimulation applied to the PP. Serum oxidative stress biomarkers [total thiol group (TTG) and superoxide dismutase (SOD)] were measured. The results showed the HFD impaired LTP induction in the PP-DG synapses. This conclusion is supported by decreased EPSP slope and PS amplitude of LTP. R. damascena supplementation in HFD animals enhanced EPSP slope and PS amplitude of LTP in the granular cell of DG. Consumption of HFD decreased TTG and SOD. R. damascena extract consumption in the HFD animals enhanced TTG and SOD. These data indicate that $R$. damascena dietary supplementation can ameliorate HFD-induced alteration of synaptic plasticity, probably through its significant antioxidant effects and activate signalling pathways, which are critical in controlling synaptic plasticity.
\end{abstract}

Keywords: Rosa damascena, Long-term potentiation, Hippocampus, High-fat diet, Antioxidant, Synaptic plasticity

\section{Introduction}

Synapses in the central nervous system (CNS) endure alterations in synaptic strength, a process called synaptic plasticity [1]. Synaptic plasticity is one of the basic mechanisms in neural circuits for most models of learning and memory [2]. These changes are collectively referred to as Hebbian plasticity, which occur locally in individual

\footnotetext{
*Correspondence: alirezakomaki@gmail.com; Komaki@umsha.ac.ir †'SeyedAsaad Karimi and Somayeh Komaki contributed equally to this work

${ }^{1}$ Neurophysiology Research Center, Hamadan University of Medical Sciences, Hamadan, Iran

Full list of author information is available at the end of the article
}

synapses and include long-term potentiation (LTP) or long-term depression (LTD) [3, 4].

Numerous studies have reported that high-fat diet (HFD) consumption can alter the morphology and structure of synapses, the amounts of released neurotransmitters and synaptic plasticity in different areas of the brain, and especially in the hippocampus [5-8]. The hippocampus is one of the brain regions critical to learning and memory [9]. Furthermore, preclinical human and rodent studies have demonstrated reduction in cognitive function and whole-body efficiency following short-term and long-term usage of an HFD [8, 10-12]. Other works have identified HFD

(c) The Author(s) 2021. This article is licensed under a Creative Commons Attribution 4.0 International License, which permits use, sharing, adaptation, distribution and reproduction in any medium or format, as long as you give appropriate credit to the original author(s) and the source, provide a link to the Creative Commons licence, and indicate if changes were made. The images or other third party material in this article are included in the article's Creative Commons licence, unless indicated otherwise in a credit line to the material. If material is not included in the article's Creative Commons licence and your intended use is not permitted by statutory regulation or exceeds the permitted use, you will need to obtain permission directly from the copyright holder. To view a copy of this licence, visit http://creativecommons.org/licenses/by/4.0/. 
consumption, as a risk factor for Alzheimer disease (AD) development [13].

Although the pathogenesis of synaptic plasticity and cognitive impairment following consumption of an HFD has not been fully clarified, factors, such as metabolic disorder [14], brain inflammation [15], brain insulin resistance [16], and oxidative stress [17], are believed to play probable roles.

Given the increasing universal burden of HFD consumption and obesity, an emerging issue of dementia related to HFD consumption, understanding the impacts of HFD consumption on learning and memory related mechanism(s), identification and recognizing of potential underlying mechanisms, and finding effective beneficial approaches are vital. However, until now, no effective treatments are available for the management of HFD-induced hippocampal-dependent memory and synaptic plasticity deficits. High level of inflammation and oxidative stress induced by a HFD is one of the main reasons for the reduction in synaptic plasticity $[18,19]$ and impaired cognitive function $[20,21]$. Oxidative stress produces excessive reactive oxygen species (ROS), primarily due to imbalances in oxidative to reducing species [22, 23].

It has been shown that Rosa damascena ( $R$. damascena) or Damask Rose can reduce oxidative toxicity, and has a key role in ROS disarm [24]. In our previous work, we demonstrate that treatment with the hydroalcoholic extract of $R$. damascena can prevent cognitive impairment caused by the consumption of an HFD, as measured by the passive avoidance learning test [25]. Since LTP is one of the basic mechanisms for learning and memory, in this study, we examined the effects of $R$. damascena on LTP.

$R$. damascena known as "Gole Mohammadi" in Iran is one of the most important species of Rosaceae family flowers [26]. $R$. damascena is one of the most famous ornamental plants in herbal medicine and is used as a traditional remedy in Iran [26] because of its sedative [27], anti-inflammatory [28, 29], antibacterial [30], analgesic [31], antioxidant [30, 32], anticancer and pain relief $[33,34]$ effects. Extracts of this plant are also used in beauty products and perfumes in multiple countries [30,35].

Considering the beneficial effects of $R$. damascena, here, we assessed the effect of hydroalcoholic extract of $R$. damascena on serum oxidative stress biomarkers and in vivo hippocampal synaptic plasticity (long-term potentiation, LTP) in the perforant pathway (PP)dentate gyrus (DG) pathway in adult rats fed with an HFD.

\section{Methods}

\section{Ethics statement}

All experimental procedures using rats were conducted in accordance with the animal care and use guidelines approved by the institutional ethics committee at Hamadan University of Medical Sciences and were performed in accordance with the National Institutes of Health Guide for Care and Use of Laboratory Animals [36]. All efforts were made to minimize suffering. The operations that could cause pain and distress were performed in another room in the absence of other animals.

\section{Animals and experimental design}

Adult male Wistar rats weighing 200-250 g obtained from Pasteur Institute of Tehran, Iran. The animals were housed in an air-conditioned room at $22 \pm 2{ }^{\circ} \mathrm{C}$ with a 12-h light/dark cycle. The animals were kept in cages with 2-3 rats in each cage. The animals had free access to water and standard or high-fat rat chow. Animals were randomly assigned to four groups of 6-8 animals each: (1) control (received standard diet), (2) HFD (received high-fat diet only), (3) HFD + Ext (received HFD plus $1 \mathrm{~g} / \mathrm{kg}$ bw hydroalcoholic extract of $R$. damascena, (4) Standard diet $+1 \mathrm{~g} / \mathrm{kg}$ bw hydroalcoholic extract of $R$. damascena (Ext group). The extract $(1 \mathrm{~g} / \mathrm{kg}$ bw daily) was administered by oral gavage for 1 month [25, 37, 38]. Animals were maintained on standard diet or HFD regimes as per the protocol for 11 weeks. After 90 days, LTP was induced in area DG with highfrequency stimulation (HFS). Experimental design and timeline are shown in Fig. 1.

\section{High-fat diet}

Animals in the HFD and HFD + extract groups were fed an HFD composed of a standard diet (67.7\%) with $8.3 \%$ ghee, $4.05 \%$ hydrogenated oil, $0.85 \%$ soybean oil, $0.8 \%$ sodium cholate, $1.0 \%$ cholesterol and $17.3 \%$ sugar [12, $25,39,40]$. For concocting HFD, standard diet chows were powdered and this powder was mixed with a certain percentage of materials in the mixture and then came in the form of pellets. For feeding experiments, male rats were placed in cages and were fed with either standard diet (Behparvar, Iran) or HFD. Animals had free access to the HFD for 3 months [25]. The composition of standard diets includes $21 \%$ protein, $3.69 \%$ fat, $32.5 \%$ carbohydrates, and $5.5 \%$ raw fiber.

\section{Preparation of extract}

For the preparation of the hydroalcoholic $R$. damascena extract, $R$. damascena petals were purchased from a flower market (Hamadan, Iran) and identified 


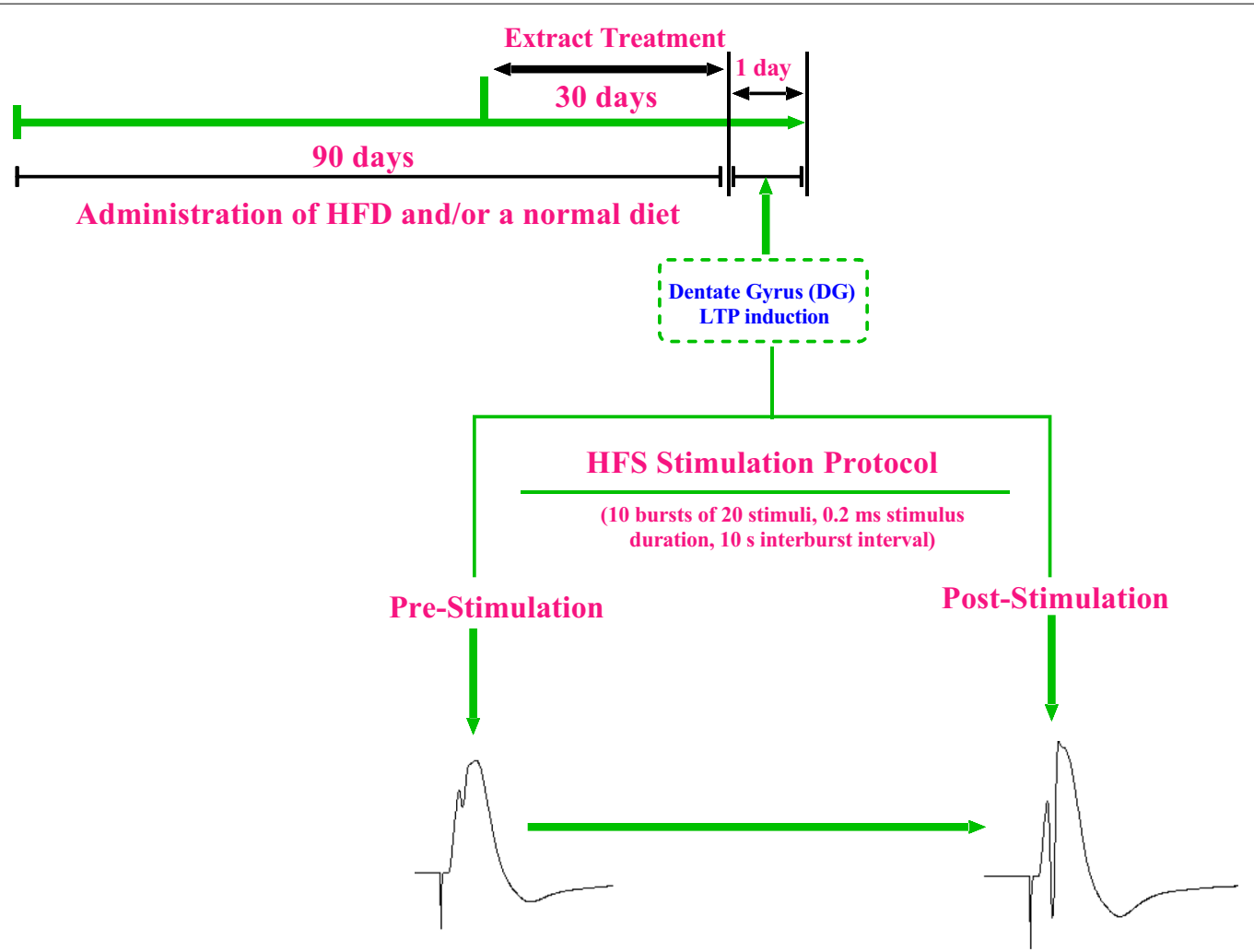

Fig. 1 Experimental design and timeline. Animals were maintained on HFD or standard diet regimes as per the protocol for 90 days before subjecting them for electrophysiological recording. The extract (1 g/kg bw daily) was administered by oral gavage for 30 days. After that, once a stable baseline was observed for at least 40 min, LTP was induced by applying HFS consisting of 10 bursts of 20 stimuli, 0.2 ms stimulus duration, 10 s interburst interval in the DG of rats. HFS; high-frequency stimulation

and authenticated at the Botanic Institute of the Hamadan University of Medical Sciences. These petals were dried in a room free of sunlight and then ground into a powder. This powder was then dissolved in 98\% ethanol and extracted using distilled water and ethanol (1:1 $\mathrm{v} / \mathrm{v}$ ) as a solvent. This extract was filtered and concentrated under reduced pressure on a rotary evaporator. It was finally freeze-dried at $-80{ }^{\circ} \mathrm{C}$. The extract was dissolved in water and prepared fresh daily in our lab and $1 \mathrm{~g} / \mathrm{kg}$ bw was administered daily by oral gavage for 1 month. Doses were chosen according to previously published data [25, 31, 41-43]. The total phenolic and flavonoid content of $R$. damascena were measured by Folin-Ciocalteu reaction and colorimetric assay, respectively [25].

The median lethal dose $\left(\mathrm{LD}_{50}\right)$ of this plant extract has been reported previously [44-47]. Oral $\mathrm{LD}_{50}$ of $R$. damascena and rose absolute was $>5 \mathrm{~g} / \mathrm{kg}$ in rats and dermal $\mathrm{LD}_{50}$ of $R$. damascena was $>2.5 \mathrm{~g} / \mathrm{kg}$ in $\mathrm{rab}-$ bits $[44,47]$. Consistent with results of another study, $\mathrm{LD}_{50}$ was determined $6 \mathrm{~g} / \mathrm{kg}$ [45]. Additionally, it has been shown that an $\mathrm{LD}_{50}$ dose of $2 \mathrm{~g} / \mathrm{kg}$ and higher than
$2 \mathrm{~g} / \mathrm{kg}$ is categorized as unclassified and therefore the extract is found to be safe [46].

The potential toxic results of $R$. damascena infusion in dogs at doses $90-1440 \mathrm{mg} / \mathrm{kg} /$ day $(0.5-8$ times of human uses) for 10 successive days discovered a minimal nephrotoxic or hepatotoxic effect. Therefore, it might also have hepatotoxic consequences at extraordinary high doses [48]. In another experiment, the ethanol extract of $R$. damascena failed to show any mortality and toxic manifestations up to the dose of $3200 \mathrm{mg} / \mathrm{kg}$ [46].

$\mathrm{IC}_{50}$ values of ethanol and watery extract of $R$. damascena have been discovered to be 18.46 and $22.1 \mathrm{lg} / \mathrm{ml}$ [49]. In another study, $\mathrm{IC}_{50}$ value of the extract in free radical scavenging was $2.24 \mathrm{lg} / \mathrm{ml}$ and in fat peroxidation assays was $520 \mathrm{lg} / \mathrm{ml}$ and fat peroxidation assays, respectively [50].

\section{Surgical procedure, electrophysiological recording and LTP induction}

Hydroalcoholic extract of Rosa damascena was administered intragastrically by gavage once a day for 1 months. Then, the rats were anesthetized with urethane, and 
placed into a stereotaxic apparatus for surgery, electrode implantation and field potential recording. The methodologies used in this section were similar to prior studies that published by our laboratory [5, 51-54]. Briefly, under urethane anesthesia induced by intraperitoneal injection $(1.5 \mathrm{~g} / \mathrm{kg})$, rats' head was fixed in a stereotaxic apparatus for surgery and recording. A heating pad was used to maintain the temperature of the animals at $36.5 \pm 0.5^{\circ} \mathrm{C}$. Small holes were drilled in the skull. Afterwards, two bipolar electrodes, made of stainless steel with Teflon cover $(125 \mu \mathrm{m}$ diameter, Advent Co., UK) were positioned in the right cerebral hemisphere. The stimulating electrode was placed in the perforant pathway (PP) [:AP: $-8.1 \mathrm{~mm}$ from bregma; ML: $+4.3 \mathrm{~mm}$ from midline; DV: $3.2 \mathrm{~mm}$ from the skull surface], while the recording electrode was positioned in the dentate gyrus (DG) granular cell layer [AP: $-3.8 \mathrm{~mm}$ from bregma; ML: $+2.3 \mathrm{~mm}$ from midline; DV: $2.7-3.2 \mathrm{~mm}$ from the skull surface] according to the Paxinos and Watson atlas of the rat brain $[5,55]$. The electrodes were lowered very slowly $(0.2 \mathrm{~mm} / \mathrm{min})$ from cortex to the hippocampus, to minimize trauma to the brain tissue.

Input-output current profiles were obtained by stimulating the PP to determine the stimulus intensity to be used in each animal (40\% maximal population spike). Single $0.1 \mathrm{~ms}$ biphasic square wave pulses were delivered through constant current isolation units (A365 WPI) at a frequency of $0.1 \mathrm{~Hz}$.

The field potential recordings were obtained in the granular cells of the DG following stimulation of the PP. Test stimuli were delivered to the PP every $10 \mathrm{~s}$. Electrodes were positioned to elicit the maximum amplitude of population spike (PS) and field excitatory post-synaptic potentials (fEPSP). After ensuring a steady-state baseline response, which was taken about $40 \mathrm{~min}$, LTP was induced using a high-frequency stimulation (HFS) protocol of $400 \mathrm{~Hz}$ (10 bursts of 20 stimuli, $0.2 \mathrm{~ms}$ stimulus duration, $10 \mathrm{~s}$ interburst interval) at a stimulus intensity that evoked a PS amplitude and field EPSP slope of $80 \%$ of the maximum response. Both fEPSP and PS were recorded 5, 30, and $60 \mathrm{~min}$ after the HFS to determine any changes in the synaptic response of DG neurons. For each time point, 10 consecutive evoked responses were averaged at $10 \mathrm{~s}$ stimulus interval [56-58].

For stimulations, the parameters of the stimuli were defined in homemade software and were sent via a data acquisition board linked to a constant current isolator unit (A365 WPI, USA) prior delivery to the PP through the stimulus electrodes. The induced field potential response from the DG, was passed through a preamplifier, then was amplified $(1000 \times)$ (Differential amplifier DAM 80 WPI, USA), and filtered (band pass $1 \mathrm{~Hz}$ to $3 \mathrm{kHz}$ ). This response was digitized at a sampling rate of
$10 \mathrm{kHz}$, and was observable on a computer (and an oscilloscope). It was saved in a file to facilitate later offline analysis.

\section{Measurement of evoked potentials}

The evoked field potential in the DG has two components: PS and fEPSP. During electrophysiological recordings, changes in PS amplitude and fEPSP slope were measured [5].

PS amplitude and EPSP slope were calculated according to Eqs. (1) and (2), respectively (see Fig. 2).

$$
\begin{aligned}
& E P S P=\frac{\Delta V}{\Delta T}, \\
& P S=\frac{\Delta V_{1}+\Delta V_{2}}{2},
\end{aligned}
$$

where (see Fig. 2). $\Delta \mathrm{V}=$ the potential difference between points $\mathrm{c}$ and $\mathrm{d} . \Delta \mathrm{T}$ : Time difference between points a and b. $\Delta \mathrm{V} 1=$ the potential difference between points $\mathrm{e}$ and $\mathrm{f}$. $\Delta \mathrm{V} 2=$ the potential difference between points $\mathrm{f}$ and $\mathrm{g}$.

\section{Blood sampling and biochemical analyses}

At the end of the study, animals were anesthetized with urethane (ethyl carbamate, $1.8 \mathrm{~g} / \mathrm{kg}$; i.p.). Blood samples were taken from the portal vein and centrifuged at $3000 \mathrm{rpm}$ for $10 \mathrm{~min}$ at $4{ }^{\circ} \mathrm{C}$. Plasma measurements were performed for the assay of serum oxidative stress biomarkers [total thiol groups (TTG), and superoxide dismutase (SOD)].

\section{Statistical analysis}

Data were presented as mean \pm SEM and processed by commercially available software GraphPad Prism ${ }^{\circledR}$ 8.0.2. The data normality test was performed using

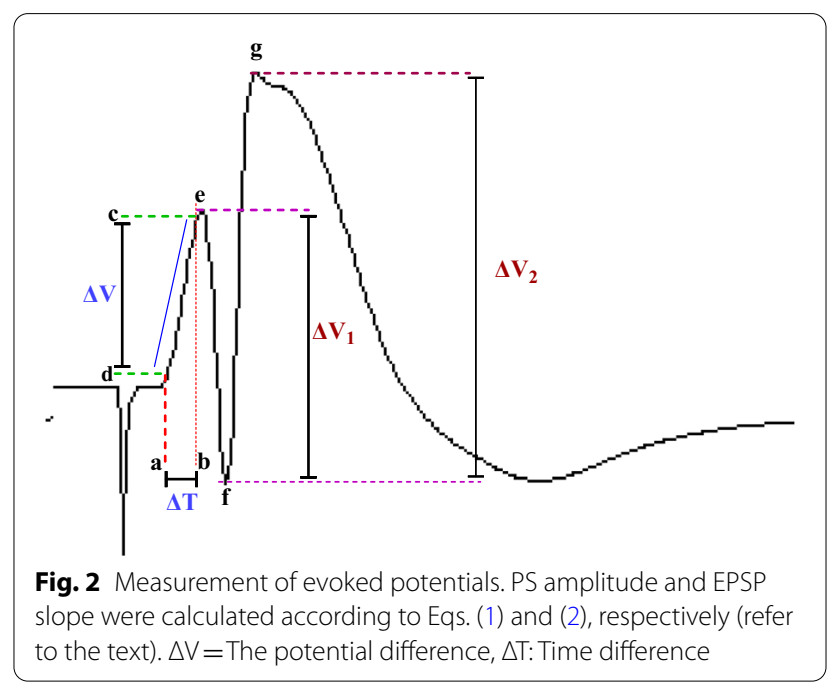


Shapiro-Wilk test. Oxidative stress data were analyzed by one-way ANOVA and Tukey's post hoc test. LTP data were analyzed by two-way repeated measures ANOVA followed by Bonferroni test. LTP data were normalized to the mean value of fEPSP slopes and PS amplitude recorded prior to the induction of LTP (Eq. 3) [53, 59, $60]$, and reported as mean \pm SEM. P values $<0.05$ were considered significant.

$$
\mathrm{LTP}=\frac{\text { the EPSP or PS value after HFS induction } \times 100 \%}{\text { the average EPSP or P Satbaseline }} .
$$

\section{Results}

\section{Effects of $R$. damascena extract on the biomarkers}

\section{of oxidative stress in rats fed with high-fat diet}

Thiol concentration increases in oxidative stress conditions [61]. The total thiol status in the body, especially thiol groups present in proteins are considered as major plasma antioxidants in vivo, and most of them are present over albumin [62], and they are the major reducing groups present in our body fluids [63]. There was a significant difference in the case TTG among the experimental groups of rats $(\mathrm{F}(3,33)=7.565, \mathrm{P}=0.0006$, One-way ANOVA, Fig. 3a). As illustrated in Fig. 4a, Consumption of HFD decreased TTG in compare with control group $(\mathrm{P}=0.0391$, Fig. 3a). $R$. damascena extract consumption in the HFD group enhanced TTG $(\mathrm{P}=0.043)$. Superoxide dismutases (SODs) constitute a very important antioxidant defense against oxidative stress in the body [64]. The impact of HFD and $R$. damascena extract on SOD concentration in serum was evaluated. There was a significant difference in the case of SOD among the experimental groups of rats $(\mathrm{F}(3,32)=18.37, \mathrm{P}<0.0001$, One-way ANOVA, Fig. 3b). As illustrated in Fig. 3b, HFD decreased SOD in serum compared with the control group $(\mathrm{P}=0.0045$, Fig. $3 \mathrm{~b})$. Treatment of HFD animals
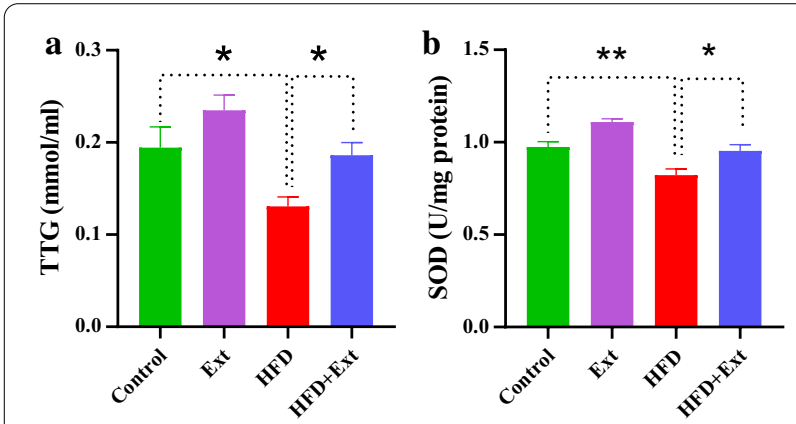

Fig. 3 Effect of high-fat diet (HFD) and R. damascena extract administration on serum levels of total thiol groups (TTG) (a) and superoxide dismutase (SOD) (b). Data presented as means \pm S.E.M. ${ }^{*} p<0.05$, and ${ }^{* *} p<0.01$

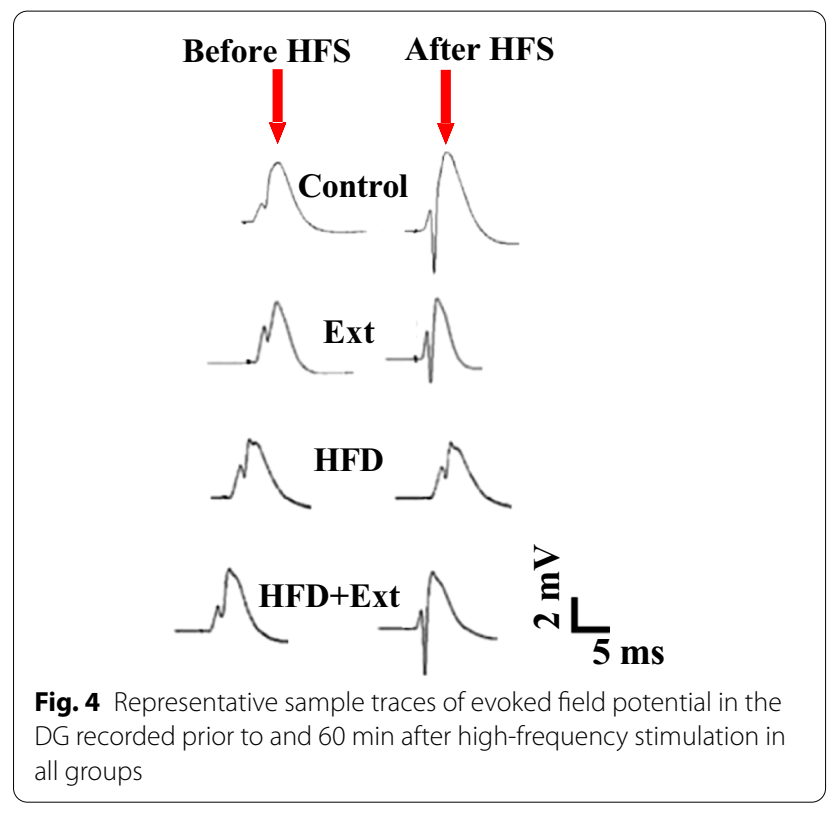

with $R$. damascena extract increased SOD concentration $(\mathrm{P}=0.0170)$.

Effects of R. damascena extract on the field excitatory post-synaptic potential (fEPSP) slopes of granular cells in the DG of rats fed with high-fat diet

Field potential recordings were obtained in the granular cells in the DG following stimulation of the PP. Representative example of evoked field potential in the DG recorded prior to and $60 \mathrm{~min}$ after high-frequency stimulation is shown in Fig. 4. The effects of $R$. damascena extract on the EPSP slopes and PS amplitudes of rats

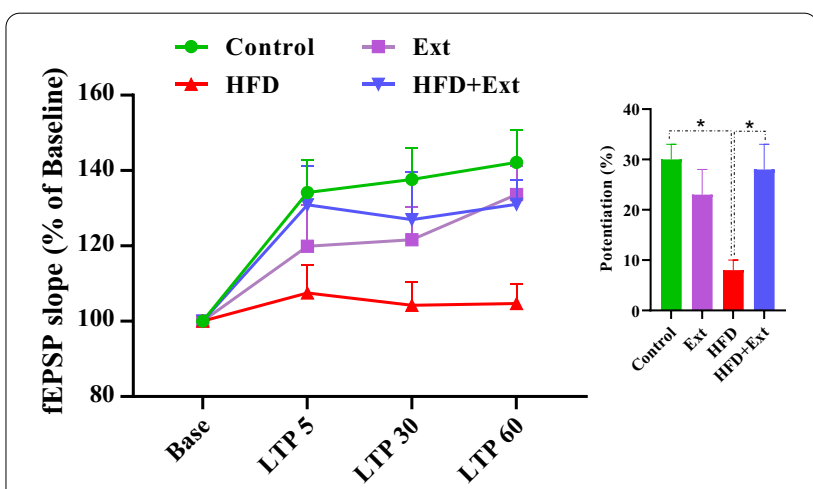

Fig. 5 Time-dependent changes in hippocampal responses to perforant path stimulation following an HFS. LTP of the EPSP slope in area DG granular cell synapses of the hippocampus are significantly different between groups. Left panel shows fEPSP slope change (\%) vs. time following HFS in different experimental groups. Bar graphs show the average fEPSP slope change (\%) during 60 min post-HFS. Data are expressed as means \pm SEM $\%$ of baseline. ${ }^{*} P<0.05$ 


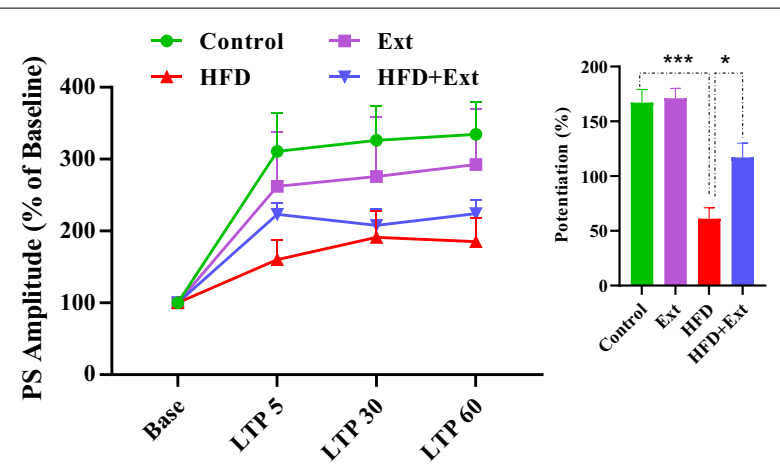

Fig. 6 Time-dependent changes in hippocampal responses to perforant path stimulation following HFS. LTP of the PS amplitude in area DG granular cell synapses of the hippocampus are significantly different between groups. Left panel shows PS amplitude change (\%) vs. time following HFS in different experimental groups. Bar graphs show the average PS amplitude change (\%) during $60 \mathrm{~min}$ post-HFS. Data are expressed as means \pm SEM \% of baseline. ${ }^{*} \mathrm{P}<0.05$, ${ }^{* * *} P<0.001$

fed with high-fat diet are shown in Figs. 5 and 6, respectively. We found that HFS did not induce LTP in rats fed with high-fat diet $[\mathrm{F}(3,24)=0.3207, \mathrm{P}=0.8103$, one-way ANOVA]. The percent change in slope of fEPSP immediately and 60 min after HFS was significantly smaller in rats fed with high-fat diet than in control rats. We used a two-way analysis of variance to reveal the variability between the groups. Our results showed a significant effect of time points $[\mathrm{F}(3,57)=26.94, \mathrm{P}<0.0001]$ and treatment $[\mathrm{F}(3,19)=3.390, \mathrm{P}=0.0393]$ in slope of EPSP of the granular cell of DG (Fig. 5). Our post hoc analysis indicated significant differences between the control group and the HFD animals. Slope of EPSP decreased in the HFD group respect to control group $(\mathrm{P}<0.05$, Fig. 5). $R$. damascena extract consumption in the HFD group enhanced EPSP slope of the granular cell of DG $(\mathrm{P}<0.05$, Fig. 5). The percent change in slope of fEPSP immediately and $60 \mathrm{~min}$ after HFS was significantly greater in HFD + Ext group than in HFD group.

\section{Effects of $R$. damascena extract on the PS amplitude of granular cells in the DG of rats fed with high-fat diet}

Our results showed a significant effect of time points $[\mathrm{F}(3,57)=29.84, \mathrm{P}<0.0001]$ and treatment $[\mathrm{F}(3$, $19)=8.497, \mathrm{P}=0.0218]$ in PS amplitude of the granular cell of DG (Fig. 6). Our post hoc analysis indicated significant differences between the control group and the HFD animals $(\mathrm{P}<0.05$, Fig. 6). PS amplitude decreased in the HFD group with respect to control group. $R$. damascena extract consumption in the HFD group enhanced PS amplitude of the granular cell of DG $(\mathrm{P}<0.05$, Fig. 6).

\section{Discussion}

This study assessed the influence of the administration of $R$. damascena on in vivo hippocampal LTP in the PP-DG pathway in adult rats fed with an HFD. In the present study, we showed that the HFD impaired LTP induction in the PP-DG synapses. This conclusion is supported by decreased EPSP slope and PS amplitude of LTP. Therefore, we confirmed the observations of previous studies, in which HFD leads to synaptic plasticity impairment. Here, for the first time, we successfully identified that $R$. damascena supplementation prevents the destructive changes induced by HFD in hippocampal synaptic plasticity. Moreover, consumption of HFD decreased TTG and SOD in compare with control animals. $R$. damascena extract consumption in the HFD group enhanced TTG and SOD.

Herbal remedies with lipid lowering and antioxidant as well as anti-inflammatory activities can play a beneficial role for the management of the HFD-induced alteration of synaptic plasticity and brain glucose metabolism [60, 65]. HFD brains elicited decreased LTP relative to the control group. This HFD-induced alteration of synaptic plasticity could be a result of (a) the inability of the now insulin-resistant hippocampal neurons to generate enough neurotransmitter glutamate [66]; (b) impaired insulin signaling (Insulin receptor substrate (IRS) and Ras/Raf/ERK signaling nodes) [66, 67]; (c) decreased translocation of glucose transporters (GLUT3/GLUT4), creating a deficiency in energy substrates required for neurotransmitter production. [66, 67]; (d) reduced activation of the extracellular signal-regulated kinase/ cAMPresponse element-binding protein (ERK/CREB) pathway [67]; (e) decreased the brain-derived neurotrophic factor (BDNF) expression and downstream mRNA levels for CREB and synapsin I [68]; (f) reduction of dendritic arborization and decreased dendritic spine number, and increase in reactive astrocytes [6].

LTP elevates the post-synaptic density of AMPA receptors. Insulin modulates glutamatergic neurotransmission by inducing GluR2 subunit phosphorylation in the AMPA receptor in the hippocampus, leading to endocytosis and thus decreases the post-synaptic excitatory ability [69].

In our study, the positive effects of $R$. damascena extract on hippocampal LTP in the PP- DG pathway in the HFD + extract group were likely due to its antioxidant properties. $R$. damascena extract consumption in the HFD animals decreased oxidative stress. Also, in our work, total phenolic and flavonoid contents of $R$. damascena were $3110.10 \pm 10.20$ and $1240 \pm 14.5 \mathrm{mg}$ per $100 \mathrm{~g}$ of extract, respectively. Flavonoids have antioxidant effects associated with various diseases, such as cancer, AD, etc. $[70,71]$. Their high antioxidant capacity could 
be a result of following mechanisms [70]: (a) direct scavenging of ROS; (b) activation of antioxidant enzymes; (c) metal chelating activity; (d) reduction of $\alpha$-tocopheryl radicals; (e) inhibition of oxidases; (f) mitigation of oxidative stress caused by nitric oxide; (g) increase in uric acid levels; (h) increase in antioxidant properties of low molecular antioxidants. It is reported that citronellol, geraniol, linalool, kaempferol and quercetin are the main components of $R$. damascena [26, 50]. These compounds have antioxidant properties [72]. It has also been shown that $R$. damascena provides protection against DNA oxidative damage through its significant antioxidant effects [73].

Emerging evidence suggests that flavonoids are able to activate signalling pathways, which are critical in controlling synaptic plasticity [74]. Their ability to activate the ERK1/2 and the protein kinase $B$ (PKB/Akt) signalling pathways, leading to the activation of the CREB. These molecular events, which converge on CREB activation and neurotrophin synthesis, are able to induce synaptic plasticity [74]. In addition to ERK and CREB activation, flavonoids results in an activation of mechanistic target of rapamycin (mTOR) and an increased expression of hippocampal activity-regulated cytoskeleton-associated protein (Arc) [75]. Arc is known to be important in LTP and has been proposed to be under regulatory control of both BDNF [76] and the ERK signaling [77]. Also, flavonoids lead to improvements in synaptic plasticity through induction of synapse growth and connectivity, increases in synaptic activity, increases in dendritic spine density and the functional integration of old and new neurons [74]. Flavonoids are also capable of influencing neurogenesis through the activation of PI3 kinase-Akt-eNOS [78]. On the other hand, HFD has a detrimental effects on neurogenesis and neural plasticity in the hippocampus $[67,79]$, which appears to be masked by flavonoids or compounds containing flavonoids [78].

\section{Conclusion}

In conclusion, the present study clearly demonstrates that treatment with the $R$. damascena can prevent synaptic plasticity impairment caused by the consumption of an HFD. These effects are likely due to the strong antioxidant properties of the extract and its ability to scavenge free radicals. Further experiments are required for determining the detail mechanism(s) of $R$. damascena action.

\section{Acknowledgements}

The authors would like to express their gratitude to the staff of the Neurophysiology Research Center for helping us to carry out this project.

\section{Authors' contributions}

All authors have assumed responsibility for data integrity and accuracy of the data analysis. Study concept and design: SAK, AK. Data acquisition: SK, MT. Data analysis and interpretation: GO, AK, SK, MK-A. Drafting of the manuscript:
AK, SAK, MK-A. Critical revision of the manuscript for important intellectual content: AK and IS. Statistical analysis: SK, GO, IS. Study supervision: AK. All authors read and approved the final manuscript.

\section{Funding}

This research was supported by a grant (Grant Number: 940222778) of the Neurophysiology Research Center, Hamadan University of Medical Sciences, Hamadan, Iran.

\section{Availability of data and materials}

All data and material are available.

\section{Declarations}

\section{Ethics approval and consent to participate}

All animal experimental procedures were performed in accordance with the guidelines for proper conduct of animal experiments issued by the Ethics Committee of the Hamadan University of Medical Sciences, and performed according to the 'Guide for the Care and Use of Laboratory Animals', prepared by the National Academy of Sciences and published by the National Institutes of Health (NIH publication 86-23 revised 1985).

\section{Consent for publication}

All the authors have approved the manuscript and agree with submission to your esteemed journal.

\section{Competing interests}

The authors confirm that there is no conflict of interest associated with this publication.

\section{Author details \\ ${ }^{1}$ Neurophysiology Research Center, Hamadan University of Medical Sci- ences, Hamadan, Iran. ${ }^{2}$ Department of Neuroscience, School of Science and Advanced Technologies in Medicine, Hamadan University of Medical Sciences, Hamadan, Iran. ${ }^{3}$ Department of Neuroscience, School of Advanced Technologies in Medicine, Iran University of Medical Sciences, Tehran, Iran. ${ }^{4}$ Neuroscience Research Center, Iran University of Medical Sciences, Tehran, Iran. ${ }^{5}$ Department of Physiology, School of Medicine, Hamadan University of Medical Sciences, Shahid Fahmideh Street, 65178/518 Hamadan, Iran.}

Received: 17 September 2020 Accepted: 29 March 2021

Published online: 29 April 2021

\section{References}

1. Bailey CH, Kandel ER, Harris KM (2015) Structural components of synaptic plasticity and memory consolidation. Cold Spring Harb Perspect Biol 7:a021758-a021758

2. Abbott LF, Nelson SB (2000) Synaptic plasticity: taming the beast. Nat Neurosci 3:1178-1183

3. Huganir R, Nicoll R (2013) AMPARs and synaptic plasticity: the last 25 years. Neuron 80:704-717

4. Turrigiano GG (2008) The self-tuning neuron: synaptic scaling of excitatory synapses. Cell 135:422-435

5. Karimi SA, Salehi I, Komaki A, Sarihi A, Zarei M, Shahidi S (2013) Effect of high-fat diet and antioxidants on hippocampal long-term potentiation in rats: an in vivo study. Brain Res 1539:1-6

6. Calvo-Ochoa E, Hernández-Ortega K, Ferrera P, Morimoto S, Arias C (2014) Short-term high-fat-and-fructose feeding produces insulin signaling alterations accompanied by neurite and synaptic reduction and astroglial activation in the rat hippocampus. J Cereb Blood Flow Metab 34:1001-1008

7. Krishna S, Keralapurath M, Lin Z, Wagner J, de La Serre C, Harn D, Filipov N (2015) Neurochemical and electrophysiological deficits in the ventral hippocampus and selective behavioral alterations caused by high-fat diet in female C57BL/6 mice. Neuroscience 297:170-181 
8. Khazen T, Hatoum OA, Ferreira G, Maroun M (2019) Acute exposure to a high-fat diet in juvenile male rats disrupts hippocampal-dependent memory and plasticity through glucocorticoids. Sci Rep 9:1-10

9. Jarrard LE (1993) On the role of the hippocampus in learning and memory in the rat. Behav Neural Biol 60:9-26

10. Edwards LM, Murray AJ, Holloway CJ, Carter EE, Kemp GJ, Codreanu I, Brooker H, Tyler DJ, Robbins PA, Clarke K (2011) Short-term consumption of a high-fat diet impairs whole-body efficiency and cognitive function in sedentary men. FASEB J 25:1088-1096

11. Kalmijn S, Launer $\sqcup$, Ott A, Witteman JC, Hofman A, Breteler MM (1997) Dietary fat intake and the risk of incident dementia in the Rotterdam study. Ann Neurol 42:776-782

12. Habibitabar E, Moridi H, Shateri H, Karimi SA, Salehi I, Komaki A, Sarihi A (2020) Chronic NaHS treatment improves spatial and passive avoidance learning and memory and anxiety-like behavior and decreases oxidative stress in rats fed with a high-fat diet. Brain Res Bull 164:380-391

13. Morris MC, Evans DA, Bienias JL, Tangney CC, Bennett DA, Aggarwal N, Schneider J, Wilson RS (2003) Dietary fats and the risk of incident Alzheimer disease. Arch Neurol 60:194-200

14. Zemdegs J, Quesseveur G, Jarriault D, Pénicaud L, Fioramonti X, Guiard BP (2016) High-fat diet-induced metabolic disorders impairs 5-HT function and anxiety-like behavior in mice. Br J Pharmacol 173:2095-2110

15. Pistell PJ, Morrison CD, Gupta S, Knight AG, Keller JN, Ingram DK, BruceKeller AJ (2010) Cognitive impairment following high fat diet consumption is associated with brain inflammation. J Neuroimmunol 219:25-32

16. Kothari V, Luo Y, Tornabene T, O'Neill AM, Greene MW, Geetha T, Babu JR (2017) High fat diet induces brain insulin resistance and cognitive impairment in mice. Biochim Biophys Acta BBA Mol Basis Dis 1863:499-508

17. Morrison CD, Pistell PJ, Ingram DK, Johnson WD, Liu Y, Fernandez-Kim SO, White CL, Purpera MN, Uranga RM, Bruce-Keller AJ (2010) High fat diet increases hippocampal oxidative stress and cognitive impairment in aged mice: implications for decreased Nrf2 signaling. J Neurochem 114:1581-1589

18. Tan BL, Norhaizan ME (2019) Effect of high-fat diets on oxidative stress, cellular inflammatory response and cognitive function. Nutrients 11:2579

19. Asadbegi M, Komaki A, Salehi I, Yaghmaei P, Ebrahim-Habibi A, Shahidi S, Sarihi A, AsI SS, Golipoor Z (2018) Effects of thymol on amyloid- $\beta$-induced impairments in hippocampal synaptic plasticity in rats fed a high-fat diet. Brain Res Bull 137:338-350

20. Ganji A, Salehi I, Nazari M, Taheri M, Komaki A (2017) Effects of Hypericum scabrum extract on learning and memory and oxidant/antioxidant status in rats fed a long-term high-fat diet. Metab Brain Dis 32:1255-1265

21. Asadbegi M, Yaghmaei P, Salehi I, Komaki A, Ebrahim-Habibi A (2017) Investigation of thymol effect on learning and memory impairment induced by intrahippocampal injection of amyloid beta peptide in high fat diet-fed rats. Metab Brain Dis 32:827-839

22. Galli F, Piroddi M, Annetti C, Aisa C, Floridi E, Floridi A (2005) Oxidative stress and reactive oxygen species. Cardiovascular disorders in hemodialysis. Karger Publishers, Basel, pp 240-260

23. Zarrinkalam E, Ranjbar K, Salehi I, Kheiripour N, Komaki A (2018) Resistance training and hawthorn extract ameliorate cognitive deficits in streptozotocin-induced diabetic rats. Biomed Pharmacother 97:503-510

24. Nikolova G, Karamalakova Y, Kovacheva N, Stanev S, Zheleva A, Gadjeva $\checkmark$ (2016) Protective effect of two essential oils isolated from Rosa damascena Mill. and Lavandula angustifolia Mill, and two classic antioxidants against L-dopa oxidative toxicity induced in healthy mice. Regul Toxicol Pharmacol 81:1-7

25. Rezvani-Kamran A, Salehi I, Shahidi S, Zarei M, Moradkhani S, Komaki A (2017) Effects of the hydroalcoholic extract of Rosa damascena on learning and memory in male rats consuming a high-fat diet. Pharm Biol 55:2065-2073

26. Loghmani-Khouzani H (2007) Essential oil composition of Rosa damascena Mill cultivated in central Iran. Sci Iranica 14

27. Rakhshandah H, Hosseini M (2006) Potentiation of pentobarbital hypnosis by Rosa damascena in mice.

28. Latifi G, Ghannadi A, Minaiyan M (2015) Anti-inflammatory effect of volatile oil and hydroalcoholic extract of Rosa damascena Mill. on acetic acid-induced colitis in rats. Res Pharmaceut Sci 10:514

29. Fatemi F, Golbodagh A, Hojihosseini R, Dadkhah A, Akbarzadeh K, Dini S, Malayeri MRM (2020) Anti-inflammatory effects of deuterium-depleted water plus Rosa damascena Mill. essential oil via cyclooxygenase-2 pathway in rats. Turk J Pharmaceut Sci 17:99

30. Özkan G, Sagdiç O, Baydar N, Baydar H (2004) Note: antioxidant and antibacterial activities of Rosa damascena flower extracts. Food Sci Technol Int 10:277-281

31. Hajhashemi V, Ghannadi A, Hajiloo M (2010) Analgesic and anti-inflammatory effects of Rosa damascena hydroalcoholic extract and its essential oil in animal models. Iran J Pharmaceut Res IJPR 9:163

32. Achuthan C, Babu B, Padikkala J (2003) Antioxidant and hepatoprotective effects of Rosa damascena. Pharm Biol 41:357-361

33. Nayebi N, Khalili N, Kamalinejad M, Emtiazy M (2017) A systematic review of the efficacy and safety of Rosa damascena Mill. with an overview on its phytopharmacological properties. Complement Ther Med 34:129-140

34. Rakhshandeh H, Vahdati-Mashhadian N, Dolati K, Hosseini M (2008) Antinociceptive effect of Rosa damascena in Mice. J Biol Sci 8:176-180

35. Verma SR, Padalia CR, Chauhan A (2011) Chemical investigation of the volatile components of shade-dried petals of damask rose (Rosa damascena Mill.). Archiv Biol Sci 63:1111-1115

36. Care IoLARCo, Animals UoL, Resources NIoHDoR (1985) Guide for the care and use of laboratory animals. National Acad

37. Joukar S, Askarzadeh M, Shahouzehi B, Najafipour H, Fathpour H (2013) Assessment of safety and therapeutic efficacy of Rosa damascena $\mathrm{L}$. and Quercus infectoria on cardiovascular performance of normal and hyperlipidemic rabbits: physiologically based approach. J Toxicol 2013

38. Nazıroğlu M, Kozlu S, Yorgancıgil E, Uğuz AC, Karakuş K (2013) Rose oil (from Rosa $\times$ damascena Mill.) vapor attenuates depression-induced oxidative toxicity in rat brain. J Nat Med 67:152-158

39. Matos SL, Paula Hd, Pedrosa ML, Santos RCd, Oliveira ELd, Chianca Júnior DA, Silva ME (2005) Dietary models for inducing hypercholesterolemia in rats. Braz Arch Biol Technol 48:203-209

40. Moridi H, Sarihi A, Habibitabar E, Shateri H, Salehi I, Komaki A, Karimi J, Karimi SA (2020) Effects of post-training administration of LY341495, as an mGluR2/3 antagonist on spatial memory deficit in rats fed with high-fat diet. IBRO Reports 9:241-246

41. Kheirabadi M, Moghimi A, Rakhshande H, Rassouli MB (2008) Evaluation of the anticonvulsant activities of Rosa damascena on the PTZ induced seizures in wistar rats. J Biol Sci 8:426-430

42. Ramezani R, Moghimi A, Rakhshandeh H, Ejtehadi H, Kheirabadi M (2008) The effect of Rosa damascena essential oil on the amygdala electrical kindling seizures in rat. Pak J Biol Sci 11:746

43. Sharma M, Shakya A, Sharma N, Shrivastava S, Shukla S (2012) Therapeutic efficacy of Rosa damascena Mill. on acetaminophen-induced oxidative stress in albino rats. J Environ Pathol Toxicol Oncol 31

44. Lis-Balchin M (2006) Aromatherapy science: a guide for healthcare professionals. Pharmaceutical Press

45. Esfandiary E, Karimipour M, Mardani M, Ghanadian M, Alaei HA, Mohammadnejad D, Esmaeili A (2015) Neuroprotective effects of Rosa damascena extract on learning and memory in a rat model of amyloid- $\beta$ induced Alzheimer's disease. Adv Biomed Res 4

46. Raghavendra H, Lakshmikanth G, Ravinaik N, Samatha Y (2015) Evaluation of protective effects of Rosa damascena Mill against alloxan induced diabetic neuropathy in rats. J Global Trends Pharmaceut Sci

47. Mahboubi M (2016) Rosa damascena as holy ancient herb with novel applications. J Tradit Complement Med 6:10-16

48. Akbari M, Kazerani HR, Kamrani A, Mohri M (2013) A preliminary study on some potential toxic effects of Rosa damascena Mill. Iran J Vet Res 14:232-236

49. Himesh S, Nanda S, Singhai A, Jitender M (2012) Radical scavenging activities and natural indicator activity of aqueous and ethanolic extract of Rosa damascena. Int J Pharm Pharm Sci 4:581-586

50. Yasa N, Masoumi F, Rouhani RS, Haji AA (2009) Chemical composition and antioxidant activity of the extract and essential oil of Rosa damascena from Iran, population of Guilan

51. Komaki H, Saadat F, Shahidi S, Sarihi A, Hasanein P, Komaki A (2017) The interactive role of $\mathrm{CB} 1$ receptors and L-type calcium channels in hippocampal long-term potentiation in rats. Brain Res Bull 131:168-175

52. Salehi I, Karamian R, Komaki A, Tahmasebi L, Taheri M, Nazari M, Shahidi S, Sarihi A (2015) Effects of vitamin E on lead-induced impairments in hippocampal synaptic plasticity. Brain Res 1629:270-281

53. Omidi G, Karimi SA, Shahidi S, Faraji N, Komaki A (2020) Coenzyme Q10 supplementation reverses diabetes-related impairments in long-term 
potentiation induction in hippocampal dentate gyrus granular cells: an in vivo study. Brain Res 1726:146475

54. Wang S-Q, Li D, Yuan Y (2019) Long-term moderate intensity exercise alleviates myocardial fibrosis in type 2 diabetic rats via inhibitions of oxidative stress and TGF-B1/Smad pathway. J Physiol Sci 69:861-873

55. Paxinos G, Watson C (2005) The rat brain in stereotaxic coordinates. Elsevier Academic Press, USA

56. Taube JS, Schwartzkroin PA (1988) Mechanisms of long-term potentiation: a current-source density analysis. J Neurosci Off J Soc Neurosci 8:1645-1655

57. Karimi SA, Komaki A, Salehi I, Sarihi A, Shahidi S (2015) Role of group II metabotropic glutamate receptors (mGluR2/3) blockade on long-term potentiation in the dentate gyrus region of hippocampus in rats fed with high-fat diet. Neurochem Res 40:811-817

58. Salehi I, Komaki A, Karimi SA, Sarihi A, Zarei M (2018) Effect of garlic powder on hippocampal long-term potentiation in rats fed high fat diet: an in vivo study. Metab Brain Dis 33:725-731

59. Scott-McKean JJ, Roque AL, Surewicz K, Johnson MW, Surewicz WK, Costa A (2018) Pharmacological modulation of three modalities of cal hippocampal long-term potentiation in the ts65dn mouse model of down syndrome. Neural Plast 2018:1-14

60. Omidi G, Rezvani-Kamran A, Ganji A, Komaki S, Etaee F, Asadbegi M, Komaki A (2020) Effects of Hypericum scabrum extract on dentate gyrus synaptic plasticity in high fat diet-fed rats. J Physiol Sci 70:1-8

61. Jones DP, Liang Y (2009) Measuring the poise of thiol/disulfide couples in vivo. Free Radical Biol Med 47:1329-1338

62. Prakash M, Upadhya S, Prabhu R (2004) Protein thiol oxidation and lipid peroxidation in patients with uraemia. Scand J Clin Lab Invest 64:599-604

63. Mungli P, Shetty MS, Tilak P, Anwar N (2009) Total thiols: biomedical importance and their alteration in various disorders. Online J Health Allied Sci 8

64. Younus H (2018) Therapeutic potentials of superoxide dismutase. Int J Health Sci 12:88

65. Semwal P, Kapoor T, Anthwal P, Sati B, Thapliyal A (2014) Herbal extract as potential modulator and drug for synaptic plasticity and neurodegenerative disorders. Int J Pharm Sci Rev Res 25:69-79

66. Liu Z, Patil I, Sancheti H, Yin F, Cadenas E (2017) Effects of lipoic acid on high-fat diet-induced alteration of synaptic plasticity and brain glucose metabolism: a PET/CT and 13 C-NMR study. Sci Rep 7:1-13

67. Liu Z, Patil IY, Jiang T, Sancheti H, Walsh JP, Stiles BL, Yin F, Cadenas E (2015) High-fat diet induces hepatic insulin resistance and impairment of synaptic plasticity. PLoS ONE 10:e0128274

68. Molteni R, Wu A, Vaynman S, Ying Z, Barnard R, Gomez-Pinilla F (2004) Exercise reverses the harmful effects of consumption of a high-fat diet on synaptic and behavioral plasticity associated to the action of brainderived neurotrophic factor. Neuroscience 123:429-440
69. Ahmadian G, Ju W, Liu L, Wyszynski M, Lee SH, Dunah AW, Taghibiglou C, Wang Y, Lu J, Wong TP (2004) Tyrosine phosphorylation of GluR2 is required for insulin-stimulated AMPA receptor endocytosis and LTD. EMBO J 23:1040-1050

70. Procházková D, Boušová I, Wilhelmová N (2011) Antioxidant and prooxidant properties of flavonoids. Fitoterapia 82:513-523

71. de Andrade Teles RB, Diniz TC, Costa Pinto TC, de Oliveira Júnior RG, Gama e Silva M, de Lavor ÉM, Fernandes AWC, de Oliveira AP, de Almeida Ribeiro FPR, da Silva AAM (2018) Flavonoids as therapeutic agents in Alzheimer's and Parkinson's diseases: a systematic review of preclinical evidences. Oxidative Med Cell Longevity 2018:1-21

72. Brewer M (2011) Natural antioxidants: sources, compounds, mechanisms of action, and potential applications. Comprehensive Rev Food Sci Food Saf 10:221-247

73. Kalim MD, Bhattacharyya D, Banerjee A, Chattopadhyay S (2010) Oxidative DNA damage preventive activity and antioxidant potential of plants used in Unani system of medicine. BMC Complement Altern Med 10:77

74. Spencer JP (2009) The impact of flavonoids on memory: physiological and molecular considerations. Chem Soc Rev 38:1152-1161

75. Williams CM, El Mohsen MA, Vauzour D, Rendeiro C, Butler LT, Ellis JA, Whiteman M, Spencer JP (2008) Blueberry-induced changes in spatial working memory correlate with changes in hippocampal CREB phosphorylation and brain-derived neurotrophic factor (BDNF) levels. Free Radical Biol Med 45:295-305

76. Yin Y, Edelman GM, Vanderklish PW (2002) The brain-derived neurotrophic factor enhances synthesis of Arc in synaptoneurosomes. Proc Nat Acad Sci 99:2368-2373

77. Waltereit R, Dammermann B, Wulff P, Scafidi J, Staubli U, Kauselmann G, Bundman M, Kuhl D (2001) Arg3. 1/Arc mRNA induction by $\mathrm{Ca}^{2+}$ and CAMP requires protein kinase $\mathrm{A}$ and mitogen-activated protein kinase/ extracellular regulated kinase activation. J Neurosci 21:5484-5493

78. Vauzour D, Vafeiadou K, Rodriguez-Mateos A, Rendeiro C, Spencer JP (2008) The neuroprotective potential of flavonoids: a multiplicity of effects. Genes Nutr 3:115

79. Nam SM, Kim JW, Kwon HJ, Yoo DY, Jung HY, Kim DW, Hwang IK, Seong JK, Yoon YS (2017) Differential effects of low-and high-dose zinc supplementation on synaptic plasticity and neurogenesis in the hippocampus of control and high-fat diet-fed mice. Neurochem Res 42:3149-3159

\section{Publisher's Note}

Springer Nature remains neutral with regard to jurisdictional claims in published maps and institutional affiliations.
Ready to submit your research? Choose BMC and benefit from:

- fast, convenient online submission

- thorough peer review by experienced researchers in your field

- rapid publication on acceptance

- support for research data, including large and complex data types

- gold Open Access which fosters wider collaboration and increased citations

- maximum visibility for your research: over 100M website views per year

At BMC, research is always in progress.

Learn more biomedcentral.com/submissions 